\title{
Trabalho doméstico e desproteção previdenciária no Brasil: questões em análise
}

\author{
Rita de Lourdes de Lima \\ Universidade Federal do Rio Grande do Norte (UFRN) \\ Amanda Kelly Belo da Silva \\ Universidade Federal do Rio Grande do Norte (UFRN)
}

\author{
Franciclézia de Sousa Barreto Silva \\ Universidade do Estado do Rio Grande do Norte (UERN) \\ Milena Gomes de Medeiros \\ Universidade Federal do Rio Grande do Norte (UFRN)
}

\section{Trabalho doméstico e desproteção previdenciária no Brasil: questões em análise}

Resumo: Este artigo traz uma análise do trabalho doméstico no Brasil, considerando as discussões de gênero, a divisão sexual do trabalho e a previdência social, que hoje se encontram sob a égide das transformações societárias oriundas do final do século 20. Para isto, estabeleceu-se um diálogo com diversos estudiosos, como: Boschetti, Hirata, Kergoat, Nogueira e Saffioti, entre outros. Inicialmente, partindo do conceito de gênero, faz-se um resgate histórico da divisão sexual do trabalho na sociedade capitalista, considerando, particularmente, as desigualdades entre homens e mulheres no mercado de trabalho. Por fim, considerando a seguridade social no Brasil, no quadro de contrarreformas da previdência, apresenta-se as implicações desta realidade para o trabalho feminino e, especificamente, para o trabalho doméstico, constatando a real desproteção social a que está submetida toda classe trabalhadora.

Palavras-chave: gênero, divisão sexual do trabalho, previdência social.

\section{Domestic Labor and the Lack of Social Security Protection in Brazil: Questions for Analysis}

Abstract: This article analyzes domestic labor in Brazil, considering gender, the sexual division of labor and social security, which are influenced by the social transformations of the late 20th century. To do so, a dialog was established with various theoreticians including: Boschetti, Hirata, Kergoat, Nogueira and Saffioti. A historical review of the sexual division of labor in capitalist society is conducted, utilizing the concept of gender and examining inequality between men and women in the work force. Then, looking at social security in Brazil, the implications of counter reforms to the system for female labor and particularly for domestic work are analyzed, identifying the real lack of social protection suffered by the entire working class.

Key words: gender, sexual division of labor, social security. 


\section{Introdução}

Entendemos a discussão do gênero, hoje, como um questionamento à construção sócio-histórica e cultural conservadora que tem determinado, ao longo dos séculos, os comportamentos de homens e mulheres com base nos seus corpos sexuados. Sempre houve uma lógica de normas e representações em torno desses comportamentos que nos é imposta como "natural", mas que é, na realidade, uma construção da sociedade interessada em manter essa concepção.

Ao longo da história humana, as relações entre os sexos e os papéis que lhes são socialmente atribuídos reproduzem relações de exploração-dominação, cabendo ao homem a detenção do poder econômicopolítico e social. Tais relações de poder também se reproduzem no mundo do trabalho, estabelecendo a divisão sexual do trabalho, que "destina" aos homens as ocupações melhor remuneradas, mais protegidas e de maior prestígio social.

A expressão Divisão Sexual do Trabalho (DST) é utilizada na linguagem sociológica com várias acepções, contudo ele remete comumente a uma abordagem descritivo-explicativa sobre a diferenciação entre os sexos nas atividades sociais, buscando interpretações para as permanências ou modificações que se dão na divisão do trabalho social. De fato, a divisão sexual do trabalho encontra-se presente em todas as sociedades e, embora suas modalidades variem fortemente no tempo e no espaço, ela é sempre estruturada por um princípio hierárquico em que $\mathrm{o}$ trabalho masculino tem sempre um valor superior ao trabalho feminino (KERGOAT, 1984). A conotação de tal termo se ajusta à preocupação com as condições de trabalho das mulheres no espaço doméstico ou no mercado de trabalho (formas de inserção, salários, condições e significado social do trabalho etc).

No estudo das novas configurações da divisão sexual do trabalho, em meio às recentes movimentações de reprodução do capital, a mão de obra feminina representa cerca de $40 \%$ da força de trabalho nos países desenvolvidos. Isto se deve, principalmente, porque as mulheres também se inserem no contexto de "aguda destrutividade", de degradação do trabalho, de fragmentação e heterogeneidade da classe trabalhadora. É o que Antunes (2007, p. 171), denomina de "[...] expressão mais profunda da crise que assola a (des)sociabilização contemporânea." Na concepção do autor em epígrafe, trata-se, da criação da "sociedade dos descartáveis", condição indispensável à manutenção do sistema de metabolismo social do capital.

O fato é que as formas desiguais de inserção das mulheres no mercado, derivadas da divisão sexual do trabalho e das relações sexuadas, têm influenciado diretamente seu acesso aos direitos sociais e, especificamente, aos direitos previdenciários, fortemen- te vinculados ao acesso ao trabalho e renda no Brasil. Ressaltamos que a problemática referente à seguridade do trabalho no Brasil, deve ser analisada tendo como referência o projeto de contrarreforma do Estado brasileiro ${ }^{1}$ nos últimos anos, bem como do processo de reestruturação produtiva, da dinâmica de mundialização do capital, regida à base mundial por um projeto econômico, social e político neoliberal.

Partindo dessas premissas, problematizaremos o trabalho doméstico no Brasil, realizado predominantemente por mulheres, e o seu acesso aos direitos previdenciários.

\section{A divisão sexual do trabalho no capitalismo: um resgate histórico}

Foram, historicamente, construídas uma determinação e uma diferenciação de comportamentos que deveriam ser adotadas por homens e mulheres. Diante da complexidade desses seres, surge a utilização do termo "gênero" para subsidiar, definir, discutir e questionar a construção histórica, social e cultural de comportamentos pré-determinados para o "ser homem" e para o "ser mulher".

No espaço da aparência visual, a construção das desigualdades pode partir das diferenças biológicas existentes entre homens e mulheres. Entretanto, no papel e no comportamento determinado para cada um deles, devemos considerar a complexa formação da produção social dos bens materiais, necessários à sobrevivência dos indivíduos, que foi construindo na sociedade uma divisão sexual do trabalho e que subsidiou as desigualdades existentes.

Os indivíduos nascem machos ou fêmeas, mas sua sexualidade, ou comportamento, não é definido por isso. Segundo Scott (1990), o termo "gênero" passou ser utilizado como uma maneira de se referir às construções sociais da relação entre os sexos, às identidades subjetivas dos homens e das mulheres, rejeitando dessa forma o determinismo biológico.

Contudo, algumas feministas não se sentindo contempladas apenas pelo termo analítico "gênero" que compreende também relações igualitárias - trouxeram para a pauta de discussão o conceito de patriarcado. Seu intuito era desvelar as relações de poder e dominação do homem sobre a mulher, direcionandoas ao convívio social, abrangendo não apenas a família, mas toda a sociedade, e que pode ser visualizada na exclusão de ou no acesso desigual a direitos (SAFFIOTI, 2004).

As análises de gênero não podem fugir às análises inseridas em seu contexto sócio-histórico. As desigualdades de gênero são aprofundadas com o incremento do sistema de produção capitalista, pois este, para garantir o desenvolvimento de funções necessárias a sua perpetuação, apela para novos 
contingentes de trabalhadores. Historicamente, a inserção feminina no mundo do trabalho vincula-se à revolução industrial, haja vista que, com o advento da maquinaria, o uso da força muscular fora se tornando desnecessária, alterando-se com isso as formas de se organizar o trabalho. Marx (1987, p. 449) ressalta bem essa inserção da mão de obra feminina, quando afirma: "O trabalho de mulheres e crianças foi à primeira palavra de ordem da aplicação capitalista da maquinaria."

No entanto essa inserção não ocorre de forma igual para homens e mulheres, tendo em vista que a propriedade privada, característica peculiar do capitalismo, fortalece e perpetua as estruturas familiares que se formam sob a ideologia patriarcal de opressão feminina. Ocorre, então, a privatização ${ }^{2}$ do trabalho socialmente considerado feminino, destinado a ser realizado na esfera do lar.

O espaço doméstico é uma esfera invisibilizada, quanto à sua importância, e desconsiderado, como produtor de riquezas. Isso ocorre, segundo Nobre e Farias (2003), porque o trabalho realizado no âmbito doméstico se desenvolve fora dos contornos do mercado, não produzindo valores de troca, configurando-se, portanto, como um trabalho não mercantil, de produção de valor de uso.

Sob o aporte das condições sócio-históricas, engendradas pelo capitalismo, percebemos que a inserção da mulher no setor de produção de riquezas tem sido direcionada prioritariamente para trabalhos considerados de natureza feminina. São trabalhos que necessitam das habilidades atribuídas primordialmente às mulheres. Considerados inferiores ao do homem e com características específicas, remontam às desigualdades de oportunidade e de acesso, como na relação entre as atividades do trabalho produtivo e as do trabalho de reprodução social.

Um elemento decisivo nessa discussão, é que a "mulher trabalhadora" é duplamente explorada, ou seja, segundo Antunes (1999, p.108), ela é explorada dentro e fora de casa e dentro e fora da fábrica. Nas palavras do autor:

[...] além da duplicidade do ato de trabalhar, ela é duplamente explorada pelo capital: desde logo por exercer, no espaço público, seu trabalho produtivo no âmbito fabril. Mas, no universo da vida privada, ela consome horas decisivas no trabalho doméstico, com que possibilita (ao mesmo capital) a sua reprodução, nessa esfera do trabalho não-diretamente mercantil, em que se criam as condições indispensáveis para a reprodução da força de trabalho de seus maridos, filhos/as e de si próprias. Sem essa esfera não - diretamente mercantil, as condições de reprodução do sistema de metabolismo social do capital estariam bastante comprometidas se não inviabilizadas.
Deste modo, a discussão do trabalho feminino e doméstico, a partir da divisão sexual do trabalho, merece destaque, pois resgata a invisibilidade do trabalho feminino ao longo da história. Kergoat (1984, p. 280-281) assinala a complexidade da reflexão acerca deste tema, afirmando que esta está indissociada das relações sociais entre homens e mulheres: "Essa teoria da divisão sexual constitui-se como alternativa aos paradigmas sociológicos que não levam em conta a 'sexualização' do social."

Outro ponto importante, e que também merece maior atenção nos estudos sobre gênero e trabalho, diz respeito ao acirramento da precarização do trabalho feminino, quando, além de considerarmos as mulheres na sociedade capitalista, inseridas em uma divisão de classe, consideramos também a discussão de raça/etnia. As mulheres trabalhadoras e, mais especificamente as mulheres negras, são as mais pobres do mundo, as mais excluídas dos empregos formais, dos lugares de decisão, da proteção social e da esfera pública (LIMA, 2002).

Com base nestas considerações, indagamos, em que condições tem se dado o trabalho feminino frente às novas configurações da divisão sexual do trabalho na contemporaneidade? Estariam sendo preservadas as velhas formas de exploração da mão de obra feminina, em se tratando das relações de gênero?

\section{As novas configurações da divisão sexual do trabalho na contemporaneidade em debate}

A análise das atuais configurações da divisão sexual do trabalho não pode se dar dissociada da análise da atual conjuntura de reprodução do capital. Isso se faz necessário, pois as bases, sob as quais essas novas configurações se metamorfoseiam e se apresentam na atualidade, se fundam nos novos movimentos e manifestações de reprodução do capital no interior das economias, especificamente pós $1970^{3}$, por um processo de reestruturação produtiva. É uma dinâmica de "mundialização do capital", regida por um projeto hegemônico do ponto de vista econômico, social e político neoliberal, que se inicia nos países desenvolvidos e se propaga posteriormente nos países subordinados, se adaptando às particularidades de cada país.

O que se observa é "alguns movimentos que aceleraram o ritmo de reprodução do capital e reproduziram a capacidade de ação dos Estados nacionais" (POCHMANN, 2004, p. 64). Isso se deveu ao fato que,

[...] o padrão sistêmico de riqueza passou a ser, desde os anos de 1970, a financeirização, com a supremacia do capital financeiro provocando maiores desequilíbrios e instabilidades nos países em 
desenvolvimento, alvos fáceis de ataques especulativos (CHESNAIS, 1994 apud POCHMANN, 2004, p. 64).

Essas transformações que se procederam de forma intensa em resposta à crise dos anos de 1970, ao programarem novas formas de produção mais "flexíveis", em substituição ao modelo taylorista/fordista, não só metamorfosearam os processos produtivos, como e principalmente, trouxeram consequências nefastas ao processo de trabalho.

Nesse ínterim, o capital age na tentativa de conseguir a adesão dos trabalhadores, os quais devem assumir esse novo projeto produtivo, denominado por Antunes (1999) de "envolvimento manipulatório", que, por trás da veiculação de "ideias" de autonomia e de colaboração, propaladas aos trabalhadores pelo capital com fins de retomar o controle sobre o trabalho, mostra a intensificação da exploração da força de trabalho de homens e mulheres, uma vez que se flexibilizou a compra e a venda desta "mercadoria".

Cria-se por um lado, e em pequena escala, um trabalhador polivalente, multifuncional, capaz de substituir muitos homens/mulheres, com a operacionalização de apenas uma máquina, mas por outro lado, uma massa imensa de trabalhadores precarizados, sem qualificação, que hoje presenciam formas de part time, emprego temporário, ou mesmo, vivenciam as agruras do desemprego. É nesse universo que as mulheres, de forma particular, inserem-se no trabalho de modo precário e desregulado. Considerando-se que, nos países avançados, as mulheres representam já $40 \%$ da força de trabalho, temse uma visão da intensidade da precarização da mão de obra feminina.

Na concepção de Meulders (2003, p. 279), os efeitos da "flexibilização", não deixaram dúvidas, quanto à fragilidade do emprego, quando fez aparecerem pobres no mercado de trabalho, trabalhadores precarizados, permanentemente ameaçados pelo desemprego, cuja renda é frequentemente inferior à linha de pobreza e, "[...] muitas vezes não se encontram em condições de beneficiar-se de uma proteção social completa: eles são os aposentados pobres de amanhã e, entre eles, as mulheres são a maioria." E ainda,

[...] as mulheres são sobre-representadas nessas formas particulares de emprego; seu acesso ao mercado de trabalho ocorre principalmente pelo viés de empregos atípicos, particularmente desfavoráveis em termos de status, horários e perspectivas de progresso (MEULDERS, 2003, p. 280).

De acordo com Hirata e Segnini (2008, p. 66), no que tange à ocupação da mão de obra brasileira na década de 1990, os dados da Pesquisa Nacional por
Amostras de Domicílios (PNAD) sinalizam para a persistência dos já conhecidos padrões diferenciados de inserção de mulheres e homens, segundo setores ou grupos de atividades econômicas. Dentre estes, o setor de serviços é tido como principal responsável pela inserção da mão de obra feminina na contemporaneidade, com maior concentração na educação, saúde, serviços sociais, serviços domésticos e outros serviços coletivos.

De fato, já na década de 1990, é possível observar uma flexibilização do trabalho das mulheres de forma abrupta, levando-as a se refugiarem em atividades ou empregos informais. No Brasil, é significativa a presença de mulheres nas atividades informais, executando-as nas ruas ou mesmo em domicílio; um trabalho sem regulamentação e, portanto, sem direitos trabalhistas e previdenciários

Segundo dados do IBGE/PNAD, citados por Bruschini e Lombardi (2003), quanto à distribuição de homens e mulheres em ocupações precárias, vemos que o total de mulheres $(40 \%$ e $36,4 \%)$ supera o total de homens $(11,2 \%$ e $10,1 \%)$ nos anos 1993 e 1998 , respectivamente. Ainda, de acordo com as referidas autoras, o percentual de trabalhadoras domésticas, que não possuem carteira de trabalho assinada, em 1993 e 1998, atinge $83,9 \%$ e $76,4 \%$, respectivamente. Esses dados reforçam o argumento das condições precárias do trabalho feminino, com baixos rendimentos e desproteção previdenciária.

Esse quadro de precarização que atinge as mulheres ocupadas permaneceu quase inalterado e continua visível nos anos posteriores. Em 2002, segundo o IBGE/PNAD, citado por Hirata e Segnini (2008), $34 \%$ da força de trabalho feminina (ou nove milhões de mulheres) ainda exerciam ocupações precárias, ou de menor qualidade no mercado de trabalho, seja como empregadas domésticas, seja em atividades sem remuneração, ou na produção para consumo próprio, ou mesmo familiar. Segundo as autoras, comparando os percentuais de mulheres e homens que exercem ocupações precárias, de acordo com os dados do IBGE/PNAD referentes ao ano de 2002, constatamos que apenas $9 \%$ de homens encontravam-se nas situações de precarização descritas.

A situação reforça-se na argumentação de Nogueira (2006). Para ela, a intersecção do trabalho com a reprodução no capitalismo, serve ao capital, tanto pela exploração da força de trabalho feminina no espaço produtivo - sob a forma de um trabalho intensivo e de baixa remuneraçõe - quanto pelas atividades realizadas por mulheres no espaço doméstico - remunerado ou não -, garantindo a manutenção dos trabalhadores atuais, bem como a reprodução de futuros trabalhadores, indispensáveis para o capital.

Conforme as formas peculiares de inserção das mulheres no âmbito do trabalho, sob a ótica da contrarreforma do Estado e da flexibilização nos processos 
de trabalho no Brasil, como entender essa "nova lógica" no que refere ao acesso dos direitos das mulheres domésticas no capitalismo contemporâneo?

\section{O trabalho e a seguridade: a desproteção social das empregadas domésticas}

A construção das categorias "trabalho" e "seguridade" está ligada à estrutura capitalista, e como tal está envolta em um processo complexo de intensa atratividade e tensão. Referimo-nos aqui ao momento da construção dos sistemas de proteção social $^{4}$, quando se exigia o ingresso do trabalhador no mercado formal de trabalho para a garantia de benefícios. Para aqueles que não se enquadrassem nessa exigência: ações assistenciais e serviços socioassistenciais. Em relação a isso, Boschetti (2003, p. 47) afirma que: "Em uma sociedade em que o direito à assistência é limitado e restrito [...], e o trabalho, embora reconhecido como direito, não é assegurado a todos, esta relação se torna excludente e provedora de iniquidades sociais."

$\mathrm{Na}$ contemporaneidade esta realidade não se esgota, pois encontramos na atual conjuntura a mesma lógica ideo-política assinalada anteriormente, principalmente, porque estas são consideradas como produto histórico, por derivarem das lutas dos trabalhadores e respondem ao atendimento das suas necessidades, reconhecidos pelo Estado, e pelos empresários. Vê-se, portanto, que a esfera da Seguridade Social, se mostra como um eixo de disputas e negociações, no âmbito da ordem burguesa, "[...] ela é sempre e continuamente objeto de investida do capital no sentido de adequá-la aos seus interesses" (MOTA, 2007, p. 40).

Dessa forma, verifica-se que o trabalho tem centralidade na constituição dos sistemas de proteção social. E é por isso que Mota (2007) afirma que as políticas de proteção social são referenciadas por princípios e valores da sociedade salarial, particularmente aquela desenhada pelo capitalismo desenvolvido e pelo trabalho organizado, no período dos anos 1940 até o final dos anos 1970, ocasião em que o capitalismo inflexiona seu padrão de acumulação, para enfrentar uma crise de dimensões globais. É nesse cenário, completa a autora, que foi necessário redefinir a seguridade social para adequá-la às novas determinações do capital.

Segundo Behring (2003), a contrarreforma do Estado é um verdadeiro processo de evocação para o passado, onde se opera a adesão ao (neo) liberalismo, às desregulamentações e às privatizações, e a vinculação a uma política fiscal que alivia a carga sobre o capital e transferindo esta para os rendimentos do trabalho. Este modelo, de ajuste estrutural, advém das propostas do Banco Mundial e do Fundo
Monetário Internacional (FMI), propostas entres as quais está a de ampliação do trabalho informal como alternativa ao desemprego.

Para a realidade brasileira, o modelo de Seguridade Social ${ }^{5}$ vigente, implementado pela Constituição de 1988, caracteriza-se, como ressalta Boschetti (2004), como um sistema "híbrido" que conjuga direitos derivados e dependentes do trabalho (previdência), com direitos de caráter universal (saúde), e direitos seletivos (assistência social) ${ }^{6}$.

Para demarcação dos acontecimentos destrutivos e a alavancada da desproteção dos trabalhadores, reportarmo-nos ao governo de Fernando Henrique Cardoso (1995-2002) que, de acordo com Boschetti (2008), implantou: a aprovação do fator previdenciário, que calcula as aposentadorias e institui um prêmio para quem permanecer em atividade; a substituição do tempo de serviço por tempo de contribuição; a aposentadoria especial apenas para os trabalhadores expostos a produtos tóxicos que institui o teto para os benefícios, desvinculando assim do salário mínimo; a aposentadoria compulsória aos 70 anos e a extinção da aposentadoria especial para professores universitários.

No governo Luiz Inácio Lula da Silva (2003-), estas mudanças continuam e são acrescidas de outras, como a proposta de instituir a contribuição dos aposentados e pensionistas. Realidade esta não aprovada para o universo dos municípios brasileiros, embora se presencie em alguns uma alíquota de contribuição que varia entre $8 \%$ e $12 \%$. De acordo com Giambiagi (2007, apud BOSCHETTI, 2008), a realidade da seguridade no Brasil será acompanhada do aumento progressivo da idade mínima para a aposentadoria; do aumento do período de contribuição e da redução do valor dos benefícios da Lei Orgânica da Assistência Social (LOAS), em até 70\%.

Dessa forma, este modelo de seguridade e, especificamente, a política previdenciária, impossibilita assegurar proteção social aos trabalhadores, excluídos do acesso ao trabalho. Essa conjuntura é mais opressora em relação ao trabalho das mulheres, pois o processo de desmantelamento da esfera pública, dos direitos conquistados e o acirramento da exploração e alienação de todos os trabalhadores, atingem mais o trabalho feminino.

Todo esse processo de mudança na questão social, de intensas transformações no espaço do trabalho feminino, tem aumentado o processo de "feminização da pobreza", agravado sob a perspectiva da chefia familiar.

De acordo com os dados do IBGE, citados por Melo (2005), a chefia de famílias por mulheres tem aumentado consideravelmente no Brasil, com um forte impacto sobre o aumento da pobreza no país ${ }^{7}$. A maioria das mulheres chefes de família são pobres, negras, com baixa escolaridade e empregadas domésticas. $\mathrm{O}$ 
crescimento da pobreza entre as mulheres tem se tornado basilar para justificar o incremento dado às políticas públicas de assistência social, voltadas especificamente para mulheres pobres e chefes de família. Essas mulheres, para sobreviverem, passam a depender de políticas assistenciais que, embora tenham um papel positivo nas suas vidas, são tímidas, focalizadas e extremamente seletivas, com pouca efetividade para virem a se tornar instrumentos de alcance de autonomia, cidadania ou para que contribuam com a superação de sua situação de pobreza ${ }^{8}$.

Todo este contexto, ora apresentado, permite-nos maior aproximação com a realidade da desproteção, que permeia o trabalho e a vida das mulheres, tornando-se mais contundente quando analisamos a situação das empregadas domésticas, que, como trabalhadoras remuneradas, carecem de uma proteção social efetiva, já que são duramente e duplamente exploradas pelo capital.

As mulheres, quando inseridas em uma análise de classe, lidam de forma diferente com as responsabilidades domésticas socialmente atribuídas. Enquanto as mulheres da classe burguesa ou média transferem estas responsabilidades para outras mulheres, em troca de salários, liberando-se para inserirem-se nos espaços de trabalho produtivo - ou para usarem seu tempo como desejarem - as mulheres da classe trabalhadora convivem com a exploração de sua força e tempo de trabalho na realização da dupla jornada. Dividem-se entre as tarefas da esfera pública e privada na vida cotidiana.

Uma particularidade, em se tratando do trabalho doméstico no Brasil, é a forma como este se insere no total das ocupações. O trabalho doméstico aparece em separado dos outros assalariados, e tal separação é justificada em razão de sua situação absolutamente particular, no sentido se ser exercido no âmbito de domicílios privados e em relação direta com os empregadores, pessoas físicas.

Carvalho (2002) assinala as dificuldades que circundam o trabalho doméstico, pois envolve dois níveis de relacionamento que se misturam no cotidiano: o familiar que, por vezes, gera uma relação afetiva com os membros da família; e o trabalhista que é a relação de trabalho e que, portanto, envolve a questão da luta de classes, muitas vezes dificultada pela relação afetiva. Esta particularidade traz dificuldades para o seu reconhecimento como trabalho e para as lutas em prol do reconhecimento dos direitos a ele inerentes.
O perfil das pessoas ocupadas neste setor carrega também a marca da formação sócio-histórica de um país escravocrata e patriarcal que, conforme já assinalamos, tem absorvido, preponderantemente, mulheres adultas, pobres, negras, chefes de família e com baixa escolaridade ${ }^{9}$, o que contribui para aumentar a discriminação social às domésticas.

Dessa forma, as contradições vividas pelas empregadas domésticas são estruturadas pela divisão sexual do trabalho e assim perpassam a realidade de todas as mulheres. No entanto, conforme observa Almeida (1982), enquanto existem mulheres que são educadas para serem patroas, outras mulheres são socializadas para serem empregadas domésticas. Estas, por sua vez, encontram no trabalho doméstico uma alternativa ao seu sustento financeiro e ao de suas famílias.

As empregadas domésticas tiveram ao longo dos anos, regulamentados o direito à carteira de trabalho e aos benefícios previdenciários e, a partir de 1972, foram incluídas entre os segurados obrigatórios da previdência social. De acordo com a Constituição Federal de 1988 (BRASIL, 1999), as empregadas domésticas passaram a ter os seguintes direitos regulamentados: salário mínimo, irredutibilidade do salário, décimo terceiro salário, repouso semanal remunerado, preferencialmente aos domingos, férias anuais remuneradas com, pelo menos, um terço a mais do que o salário normal, licença-maternidade, aposentadoria, e a sua integração à previdência social.

A Lei 10.208 de 2001 acresce ainda direitos ao Fundo de Garantia por Tempo de Serviço (FGTS) e ao seguro-desemprego, estabelecendo que assumir a contribuição que permita acesso a esses benefícios é opção do patrão, que, na maioria dos casos, opta por não contribuir, por falta de interesse ou e em benefício próprio.

As formas peculiares de
inserção da mulher no trabalho
...refletem-se no seu acesso aos
direitos previdenciários nos
países capitalistas, situação
intensificada em relação ao
trabalho das empregadas
domésticas no Brasil.

Observa-se que muitas conquistas foram alcançadas por esta categoria referente aos direitos previdenciários, apesar de não estarem regulados na previdência social da mesma forma como o são para outros segurados obrigatórios. Exemplo disso é o fato de que é o empregador doméstico que faz a opção de contribuir (ou não) para o FGTS, e isto repercute também no acesso ao seguro desemprego. Outro fator a ser considerado é que esta trabalhadora também não possui direito ao benefício previdenciário decorrente de acidentes de trabalho, ficando desprotegida quanto a esses riscos. 
Devido à forte tendência de não se registrarem vínculos trabalhistas que resguardem os direitos dessas trabalhadoras, estas ficam a mercê das decisões de seus empregadores. $\mathrm{O}$ trabalho doméstico, por se dar no espaço privado, está sujeito às próprias regras dos empregadores, que podem "negociar" com os empregados o valor do pagamento, a jornada, os dias de trabalho, a não assinatura da carteira de trabalho e o não atendimento a outros direitos conquistados ${ }^{10}$. Ou seja, as condições objetivas e subjetivas a que estão submetidas as empregadas domésticas favorecem a perpetuação de um trabalho precário e sem vínculos de proteção social, o que, para elas, vem a ser "menos mal" do que a falta do emprego.

As formas peculiares de inserção da mulher no trabalho, que se originam da divisão sexual do trabalho, e se reconfiguram diante de um contexto macrosocial, refletem-se no seu acesso aos direitos previdenciários nos países capitalistas, situação intensificada em relação ao trabalho das empregadas domésticas no Brasil.

\section{Conclusão}

As características da atual conjuntura de reestruturação do capital, como flexibilidade, desemprego, precarização das condições de trabalho, marcam a situação de muitos brasileiros e servem para esclarecer como estão ocupadas as trabalhadoras nesse país e sob quais relações estão inseridas. Demonstram, ainda, ao relacionarmos o acesso ao trabalho aos direitos sociais, o nível da desproteção social da classe trabalhadora, que, além de perpassála, faz uma diferenciação perversa sobre as mulheres, a partir da ótica da divisão sexual do trabalho.

Em um contexto de contrarreforma do Estado e na busca pela adequação dos países periféricos aos ajustes fiscais impostos pelos organismos financeiros internacionais de cunho neoliberal, o que se presencia é um enxugamento dos direitos sociais referentes ao trabalho e à seguridade social, restringindo ainda mais o acesso a eles. Assim, quem mais necessita da regulamentação destas proteções são aqueles que mais ficam excluídos do acesso a eles.

Consideramos que muitos avanços ainda são necessários para cobertura e regulamentação mais eficazes dos direitos da mulher na previdência. No entanto, entendemos que a história continua e muitas medidas ainda se fazem imprescindíveis para contemplar as mulheres empregadas domésticas no âmbito previdenciário, bem como a classe trabalhadora em geral. Para tanto, a legislação, bem como as devidas regulamentações para definir o acesso às várias vantagens trabalhistas e estendê-las a todas as categorias, precisa ser revista para que haja melhorias que realmente beneficiem àqueles em situação de trabalho precário.
Se realmente desejamos uma verdadeira emancipação humana, os direitos, aqui discutidos, devem ser encarados não como fim em si, mas situados dentro de um processo contínuo de lutas e contradições, principalmente, pela necessidade de rompimento com o atual sistema vigente.

\section{Referências}

ALMEIDA, M. S. K. de. Entre nós mulheres, elas as patroas e elas as empregadas: In: et al. Colcha de retalhos - Estudo sobre a família no Brasil. São Paulo: Brasiliense, 1982.p. 183-193.

ANTUNES, R. Os sentidos do trabalho: ensaio sobre a afirmação e a negação do trabalho. São Paulo: Boitempo, 1999.

Adeus ao trabalho? Ensaios sobre as metamorfoses e a centralidade do trabalho. São Paulo: Cortez, 2007.

BEHRING, E. R. Brasil em contrarreforma Desestruturação do Estado e perda de direitos. São Paulo: Cortez, 2003.

BOSCHETTI, I. Assistência Social no Brasil: um direito entre originalidade e conservadorismo. Brasília: GESST/ SER/UNB, 2003.

. Seguridade social e trabalho: paradoxos na construção das políticas de previdência e assistência social. Brasília: UNB/Letras livres, 2004.

Seguridade social na América Latina. In: BEHRING, E. R.; SANTOS, S. M. de M. dos (Org.). Política social no capitalismo: tendências contemporâneas. São Paulo: Cortez, 2008. p. 112-128.

BRASIL. Constituição da República Federativa do Brasil. Promulgada em 5 out. 1988. São Paulo: Atlas, 1999.

BRUSCHINI, C; LOMBARDI, M. R. Mulheres e homens no mercado de trabalho brasileiro: um retrato dos anos 1990. In: MARUANI, M; HIRATA, H. (Org.). As novas fronteiras da desigualdade: homens e mulheres no mercado de trabalho. São Paulo: Editora Senac, 2003. p. 323-356.

CARVAlHO, L. de. Emprego doméstico: produção, relações e desafios. In: LIMA, M. E. B. de et al. (Org.). Um debate crítico a partir do feminismo: reestruturação produtiva, reprodução e gênero. São Paulo: CUT, 2002.

FIORI, M. Escolaridade de empregadas domésticas sobe, mas continua baixa. R7 Notícias, Brasília, 7 out. 2009. 
Disponível em: <http://noticias.r7.com/brasil/noticias/ escolaridade-de-empregadas-domesticas-sobe-mascontinua-baixo-20091007.html >. Acesso em: 2 jan. 2010.

HIRATA, H.; SEGNINI, L. (Org.). Organização, trabalho e gênero. São Paulo: Editora Senac, 2008.

KERGOAT, D. De la condition feminine aux raports sociaux de sexes: Repères pourune évolution de la définition sociologique des catégories de sexe. Exposé fait dans le séminaire dans le Université de Provence, sur le thèrne: "La división sociale du travail". Aix-en-Provence, Jun. 1984.

LIMA, M. E. B. de et al. (Org.). Um debate crítico a partir do feminismo: reestruturação produtiva, reprodução e gênero. São Paulo: CUT, 2002.

MARX, K. O capital: crítica a economia política. São Paulo: Bertrand Brasil, 1987.

MELO, H. P. de. Gênero e pobreza no Brasil. Relatório Final do Projeto de Governabilidad Democrática de Género en America Latina y el Caribe. Brasília: CEPAL, SPM, 2005.

MEULDERS, D. A flexibilidade na Europa. In: MARUANI, M; HIRATA, H. (Org.). As novas fronteiras da desigualdade: homens e mulheres no mercado de trabalho. São Paulo: Editora Senac, 2003. p. 273-285.

MOTA, A. E. Seguridade Social Brasileira: desenvolvimento histórico e tendências Recentes. In: . et al. (Org.). Serviço Social e Saúde: formação e trabalho profissional. São Paulo: Cortez, 2007. p. 40-48.

(Org.). O mito da assistência social. Ensaios sobre Estado, política e sociedade. São Paulo: Cortez, 2008.

NOBRE, M.; FARIA, N. A produção do viver. Ensaios de economia feminista. São Paulo: Sempreviva Organização Feminista, 2003.

NOGUEIRA, C. M. O trabalho duplicado. A divisão sexual no trabalho e na reprodução: um estudo das trabalhadoras do telemarketing. São Paulo: Expressão Popular, 2006.

POCHMANN, M. (Org.). Reestruturação produtiva. Perspectivas de desenvolvimento local com inclusão social. Petrópolis: Vozes, 2004. (v.1).

SAFFIOTI, H. I. B. Gênero, patriarcado, violência. São Paulo: Perseu Abramo, 2004.

SCOTT, J. Gênero: uma categoria útil de análise histórica. Educação e Realidade, Porto Alegre, v. 16, n. 2, p. 5-22, jul./dez. 1990.

\section{Notas}

1 Termo utilizado por Bering (2003) para se referir ao aspecto regressivo das reformas feitas no Estado brasileiro a partir do governo de Fernando Collor de Melo até os dias atuais. Bering assinala tal aspecto, considerando os impostos regressivos e destrutivos e a obstacularização da agenda radicalmente progressiva e democrática demarcada pelos movimentos sociais e dos trabalhadores. Tem-se, portanto, a implementação de um conjunto de reformas orientadas para o mercado e uma adaptação passiva às novas configurações do capitalismo contemporâneo.

2 Utilizamos esta divisão entre público e privado por compreendermos que esta auxilia no entendimento da discussão de gênero e patriarcado, embora compreendamos que esta divisão em muitas discussões, toma configurações universais e a-históricas. Assim quando citamos espaço público fazemos referência a esfera de participação políticae econômica, e espaço privado, quando estamos nos referindo àquele reservado ao interior do lar.

3 Traços evidentes da crise dos anos de 1970, segundo Chesnais (1996 apudANTUNES, 1999, p. 29-30) foram: 1)a queda da taxa de lucro; 2) o esgotamento do padrão de acumulação taylorista/fordista de produção dado pela incapacidade de responder à retração do consumo que se acentuava; 3) a hipertrofia da esfera financeira; 4) a maior concentração de capitais graças às fusões entre as empresas monopolistas e oligopolistas; 5) a crise do welfare state ou do 'Estado do bem-estar social' e dos seus mecanismos de funcionamento, acarretando a crise fiscal do Estado capitalista e a necessidade de retração dos gastos públicos e sua transferência para o capital privado; 6) o incremento acentuado das privatizações, tendência generalizada às desregulamentações e à flexibilização do processo produtivo, dos mercados e da força de trabalho, entre tantos outros 'elementos contingentes' que exprimem esse novo quadro crítico.

4 Sua origem data do reconhecimento público dos riscos sociais do trabalho assalariado, ampliando-se a partir do segundo pós-guerra para proporcionar a proteção social aos trabalhadores. Portanto, os sistemas de proteção social são implementados por meio de ações assistenciais para os impossibilitados de prover seu sustento pelo trabalho, para a cobertura de riscos do trabalho, nos casos de doenças, acidentes, invalidez, desemprego e para a manutenção da renda do trabalho, seja por velhice, morte, entre outros (MOTA, 2007,p.41).

5 Os princípios da seguridade são: universalidade na cobertura, uniformidade, equivalência dos benefícios, seletividade e distributividade nos benefícios, irredutibilidade do valor dos benefícios, equidade no custeio, diversidade no financiamento e caráter democrático e descentralizado da administração. 
6 A elaboração e a aprovação da Constituição de 1988 no Brasil dão-se numa conjuntura de reorganizaçãoe mobilização dos movimentos sociais e populares, ao mesmo tempo em que, em nível mundial, o capitalismo se reorganizava e se reestruturava, a partir de medidas neoliberais. Consequentemente, a Constituição Brasileira vai expressar a conjuntura histórica daquele momento e mesclar elementos progressistas e conservadores.

7 Dados coletados em 2001: há filhos em 68,6\% dos domicílios comandados por mulheres; e do total de domicílios em que a chefia é feminina, cerca de $27 \%$ delas são pobres e $25 \%$ indigentes (IBGEapud MELO, 2005).

8 Para uma análise da política de assistência social no Brasil há uma vasta bibliografia. Para um aprofundamento da discussão, recomendamos Boschetti (2003; 2004) e Mota (2008).

9 A escolaridade entre as domésticas registrou um pequeno aumento em 2008, de 4,45 anos, em 1998, para 5,94 anos, contudo, a média de estudo no Brasil é de 7,4 anos (FIORI, 2009).

10 A maioria das empregadas domésticas no Brasil (66\%) trabalha sem carteira assinada (CARVALHO, 2002).

\section{Rita de Lourdes de Lima}

rita.pires2@gmail.com

Doutora em Serviço Social pelo Programa de PósGraduação da Universidade Federal de Pernambuco (UFPE)

Professora do Departamento de Serviço Social e Coordenadora do Programa de Pós-Graduação (PPGSS/UFRN)

\section{Franciclézia de Sousa Barreto Silva}

cleziasb@yahoo.com.br

Mestranda em Serviço Social pelo Programa de PósGraduação da Universidade Federal do Rio Grande do Norte (UFRN)

Professora do Departamento de Economia da Universidade do Estado do Rio Grande do Norte (UERN)

\section{Amanda Kelly Belo da Silva}

amandakellyuf@hotmail.com

\section{Milena Gomes de Medeiros}

milenagmedeiros@yahoo.com.br

Mestrandas em Serviço Social pelo Programa de PósGraduação da Universidade Federal do Rio Grande do Norte (UFRN)

Pesquisadoras do Grupo de Pesquisa: Trabalho, Ética e Direitos (GEPTED/UFRN)
UFRN - Programa de Pós-Graduação em Serviço Social

Campus Universitário, Av. Senador Salgado Filho, 3000

Lagoa Nova

Natal - Rio Grande do Norte

CEP: 59072-970 